\title{
SENSIBILIZAÇÃO AMBIENTAL DE ESTUDANTES DE UMA ESCOLA ESTADUAL NO NOROESTE DO RIO GRANDE DO SUL
}

\author{
ENVIRONMENTAL AWARENESS OF STUDENTS OF A STATE \\ SCHOOL IN THE NORTHWEST OF RIO GRANDE DO SUL
}

\author{
Ana Paula Nunes ${ }^{1}$ \\ Divanilde Guerra ${ }^{1}$ \\ Ramiro Pereira Bisognin ${ }^{1}$ \\ Robson Evaldo Gehlen Bohrer ${ }^{1}$ \\ Marciel Redin ${ }^{1}$ \\ Patricia Inês Kemper Back ${ }^{1}$
}

Resumo: Nas escolas, atividades relacionadas à Educação Ambiental auxiliam na formação de cidadãos conscientes, capazes de atuarem na realidade socioambiental atual e comprometidos com o meio ambiente. Desta forma, no presente trabalho objetivou-se promover a sensibilização ambiental, com ênfase no gerenciamento dos resíduos sólidos, com estudantes da Escola Estadual de Ensino Fundamental Gonçalves Dias em Três Passos/RS. O trabalho foi desenvolvido na referida escola com 15 alunos do $5^{\circ}$ ano. A primeira etapa do estudo consistiu na observação visual das condições momentâneas da separação dos resíduos sólidos na escola e determinação da massa dos mesmos. Após, realizou-se a aplicação de um questionário avaliando o conhecimento dos participantes do projeto sobre a reciclagem. Posteriormente procedeu-se a sensibilização ambiental através de palestras, oficinas pedagógicas, vídeos e jogos didáticos e, por fim, fez-se nova avaliação dos temas para atestar a efetividade da sensibilização. Como resultados observou-se que a separação inicial não estava adequada, embora os alunos apresentassem conhecimento teórico sobre a separação. As atividades de sensibilização permitiram elevada motivação e mudanças de atitudes com relação à reciclagem e reuso de materiais. Portando, pode-se inferir que os alunos do $5^{\circ}$ ano entenderam que a correta segregação e reciclagem dos resíduos é importante, pois seu descarte inadequado pode reduzir a qualidade do solo, água $\mathrm{e}$ ar e, consequentemente, afetar os seres vivos.

Palavras-chave: Educação Ambiental, Meio Ambiente, Reciclagem, Resíduos sólidos.

Abstract: In schools, activities related to Environmental Education assist in the formation of conscientious citizens, capable of acting in the current socio-environmental reality and committed to the environment. Thus, this study aimed to promote environmental awareness, with an emphasis on solid waste management, in students of 
the Gonçalves Dias State Elementary School in Três Passos / RS. The work was developed at the school with 15 th grade students. The first stage of the study consisted of visual observation of the momentary conditions for the separation of solid waste at school and determination of its mass. Afterwards, a questionnaire was applied to assess the project participants' knowledge about recycling. Subsequently, environmental awareness was provided through lectures, pedagogical workshops, videos and educational games and, finally, a new assessment of the themes was made to attest to the affectivity of awareness. As a result, it was observed that the initial separation was not adequate, although the students presented theoretical knowledge about the separation. Awareness-raising activities allowed for high motivation and changes in attitudes towards recycling and reusing materials. Therefore, it can be inferred that 5 th grade students understood that the correct segregation and recycling of waste is important, as its improper disposal can reduce the quality of soil, water and air and, consequently, affect living beings.

Keywords: Environmental education,Environment, Recycling, Solid waste.

\section{INTRODUÇÃO}

A evolução industrial e tecnológica levou o Meio Ambiente a um estado de depreciação nunca visto anteriormente. Diante desta situação, ações precisam ser urgentes e globais, agindo localmente, a fim de se obter resultados que beneficiarão a todos, universalmente. Um dos caminhos para minimizar os efeitos dessa crise é a Educação Ambiental, através de um novo modelo estratégico de crescimento econômico e desenvolvimento social com o uso sustentável dos recursos ambientais (Narcizo, 2009).

Segundo a UNESCO (2005), Educação Ambiental (EA) é uma disciplina que enfatiza a relação dos homens com o ambiente natural, as formas de conservá-lo, preservá-lo e de administrar seus recursos adequadamente. Educação está, que deve ser iniciada nos primeiros anos de vida, ainda em casa, quando as crianças aprendem, com os exemplos dos pais, como deverão agir no presente e no futuro. Depois, na escola, a Educação Ambiental deve continuar fazendo parte do dia-a-dia das crianças e jovens, sendo inserida nas diversas disciplinas e conteúdos, interdisciplinarmente (Narcizo, 2009), pois segundo Pontalti (2005), a escola é o espaço onde o aluno dará sequência ao seu processo de formação, tanto social, quanto ambiental. Ainda, neste contexto, a execução de atividades de Educação Ambiental nas escolas, poderá atingir os demais segmentos da sociedade, pois a realização de um trabalho contínuo e permanente e as transformações alcançadas, transpõem os muros da mesma (Silva e Leite, 2008). 
No Brasil, a EA foi regulamentada pela Lei nº 9.795/1999 que também institui a Política Nacional de Educação Ambiental (Figueiró, 2015). Esta possui a função de evidenciar a importância da preservação do meio ambiente e utilização de forma sustentável dos recursos naturais (Baldin, 2015), sendo considerada uma ferramenta de auxílio na promoção da sensibilização ambiental (Zamora, 2013), bem como, no trabalho direto com atitudes e com a formação de valores (Medeiros et al., 2011).

Conforme Sato (2002) há diferentes formas de incluir a temática ambiental nos currículos escolares, como atividades artísticas, experiências práticas, atividades fora de sala de aula, produção de materiais locais, projetos ou qualquer outra atividade que conduza os alunos a serem reconhecidos como agentes ativos no processo que norteia a política ambientalista.

Dentre as temáticas ambientais a serem trabalhadas, a geração de Resíduos Sólidos (RS) e sua correta separação e destinação final é um dos mais importantes e delicados temas. RS é todo material sólido ou semi-sólido indesejável que necessita ser descartado em recipiente destinado a este ato, por ter sido considerado inútil (Monteiro et al., 2001). Dentre todos os tipos, os RS englobam materiais com características diversas, desde resíduos inertes, orgânicos, embalagens de vidro, plástico, metal, papel/papelão e até resíduos perigosos, com características de toxicidade, reatividade e inflamabilidade, que devem ter destinação correta a fim de evitar danos mais severos ao meio ambiente (Dias, 2002). Além disso, estes merecem destaque, pois representam uma parcela substancial dos materiais gerados, e quando mal gerenciados, tornam-se um problema sanitário, ambiental, financeiro e social (Kgathi e Bolaane, 2001).

Portanto, desenvolver ações ambientais, como a reciclagem, com crianças é um dos primeiros passos para a formação de cidadãos conscientes, além destes, entenderem que a responsabilidade é de todos, que os atos de cada um refletem sobre o futuro de toda a humanidade. Diante do exposto, o presente trabalho tem como objetivo promover a sensibilização ambiental, com ênfase no gerenciamento dos resíduos sólidos, para estudantes de uma Escola Estadual de Ensino Fundamental no Noroeste do Rio Grande do Sul (RS).

\section{MATERIAL E MÉTODOS}

O trabalho foi desenvolvido na Escola Estadual de Ensino Fundamental Gonçalves Dias no município de Três Passos, Noroeste do RS. No ano de 2019, a escola 
atendia 164 alunos do $1^{\circ}$ ao $9^{\circ}$ ano, e contava com 29 funcionários, entre professores, atendentes e merendeiras.

As atividades deste estudo foram desenvolvidas com a alunos do $5^{\circ}$ ano, compreendendo 15 alunos.

Com relação à estrutura física, a escola está instalada em prédio próprio e conta com sala de diretoria, sala de professores, sala de ciências, cozinha, biblioteca, parque infantil e pátio descoberto. A escola possui vínculo com o Programa Integração da Associação Atlética Banco do Brasil (AABB), pelo qual os alunos participam de atividades complementares de arte, cultura e esportes.

A primeira etapa do estudo consistiu na observação das condições de separação dos resíduos sólidos na sala dos alunos do $5^{\circ}$ ano, através da verificação das lixeiras dispostas no local e posterior determinação da massa total desses resíduos, o que foi realizado com o auxílio de uma balança.

A segunda etapa consistiu na aplicação de um questionário para identificar o nível de conhecimento dos alunos sobre a correta separação dos resíduos. As questões abordadas foram: Você tem algum conhecimento sobre resíduos sólidos? Qual foi a forma de obtenção deste conhecimento? Os pais atuam na conscientização sobre os problemas que a destinação inadequada dos resíduos pode causar no meio ambiente? Você acha importante fazer a separação dos resíduos? Qual a percentagem de resíduos orgânicos, inorgânicos e resíduos produzidos em sua residência? Qual a destinação dos resíduos orgânicos e inorgânicos em sua residência?

$\mathrm{Na}$ terceira etapa procederam-se as ações de sensibilização dos alunos sobre a separação e a destinação correta dos resíduos sólidos. Esta ocorreu por meio de palestras, oficinas pedagógicas, vídeos e jogos didáticos com abordagens sobre os principais problemas causados pelo lixo, com a diferenciação do que é rejeito e o que é resíduo, além de explanação sobre a campanha de coleta seletiva do município e sua importância.

A sensibilização contou também com a confecção de cartazes e poemas envolvendo os resíduos sólidos. Para estas atividades, os alunos foram separados em quatro grupos. Ao final, os cartazes e poemas foram afixados na escola.

Posteriormente foram confeccionadas lixeiras coloridas para a sala, as quais foram identificadas com os tipos de resíduos de maior geração em sala de aula como papel, plástico, orgânico e metal. 
Por fim, como forma de avaliar a efetividade do trabalho conduzido, realizou-se a caracterização dos resíduos por meio da composição gravimétrica de cada lixeira, considerando a massa total de resíduos encontrados na sala de aula (período de 15 dias, após o processo de sensibilização) com a plena participação dos alunos, e pela reaplicação do questionário inicial.

\section{RESULTADOS E DISCUSSÃO}

A observação inicial nas lixeiras da escola permitiu identificar que os resíduos não estavam sendo descartados de forma adequada, bem como, as lixeiras não apresentavam identificação, favorecendo, desta forma, a mistura do material.

Na primeira análise, a coleta dos resíduos na sala de aula do $5^{\circ}$ ano, ao longo de 15 dias, permitiu contabilizar $210 \mathrm{~g}$ de materiais compostos por papel, plástico de balas e pirulito, erva, caroço de pêssego, rejeitos de lápis e madeira, contudo, sem permitir realizar a composição gravimétrica devido à mistura dos materiais.

Os resultados obtidos através da aplicação do questionário antes da realização das atividades de sensibilização revelaram que, em geral, os alunos apresentavam pouca informação sobre à temática. Quando questionados sobre a existência de algum conhecimento sobre resíduos sólidos, todos relataram que sim, embora as formas de como obtiveram o conhecimento tenha apresentado variações (Figura 1).

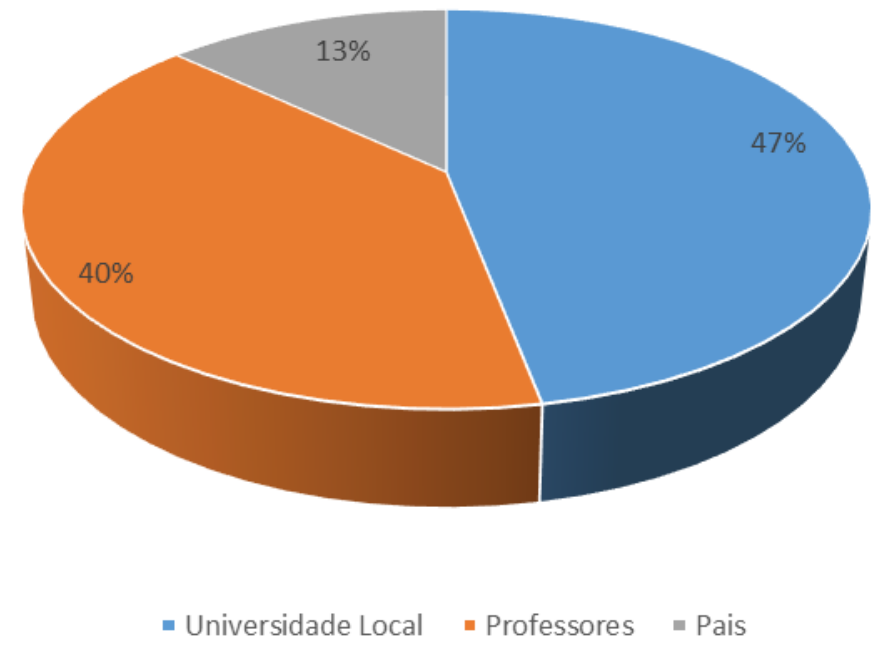

Figura 1. Formas de obtenção de conhecimento sobre resíduos sólidos. 
Como resultado, observou-se que $13 \%$ dos alunos receberam esta informação de seus pais; $40 \%$ afirmaram que receberam orientação dos profissionais da escola e $47 \%$ destacaram a atuação dos discentes da Universidade Estadual do Rio Grande do Sul (Uergs, Unidade em Três Passos), por meio da realização de uma ação de extensão sobre a reutilização do óleo de cozinha e a separação adequada dos resíduos, que foi realizada nos meses anteriores ao desenvolvimento deste estudo.

Os resultados obtidos estão em consonância com a afirmação de Medeiros et al. (2011), de que trabalhar questões ambientais é muito importante, em todos os níveis dos processos educativos e em especial nos anos iniciais da escolarização, sendo mais fácil conscientizar as crianças do que os adultos sobre as questões ambientais. $\mathrm{O}$ autor afirma ainda que a escola é o lugar onde o aluno irá dar sequência ao seu processo de socialização, e por isso, comportamentos ambientalmente corretos devem ser aprendidos na prática, e a escola deve oferecer aos alunos os conteúdos ambientais de forma contextualizada com sua realidade. Ainda, de acordo com Silveira (2013) trabalhar com temas sobre meio ambiente, mais especificamente com o lixo, é uma forma de contribuir para a formação das crianças, e capacitá-las para decidirem e atuarem gradativamente na realidade socioambiental em que estão inseridas de forma responsável.

Os alunos também foram questionados sobre a real atuação dos pais na conscientização sobre os problemas que a destinação inadequada dos resíduos pode causar no meio ambiente. Como resultados, observou-se que $80 \%$ afirmaram que em suas residências os pais falam da importância da destinação correta e dos problemas causados pela destinação inadequada dos resíduos, enquanto $20 \%$ afirmaram que os pais não conversam sobre os problemas e a destinação dos resíduos sólidos. Neste contexto, Saraiva et al. (2008) constataram que o lixo é um dos principais causadores de impactos no meio ambiente, e que os pais têm o dever de conversar com os filhos sobre a importância da separação e destinação correta dos resíduos. Ainda segundo Felix (2007), essa preocupação se eleva devido ao potencial poluidor que alguns resíduos possuem, podendo contaminar os recursos naturais.

Quanto a receber algum incentivo para separar os resíduos domiciliares, como resposta, $73 \%$ afirmaram receber orientação dos pais, ou dos profissionais da escola para separar os resíduos produzidos, enquanto que $27 \%$ afirmaram não receber qualquer tipo de incentivo. Isso evidencia a influência e a importância das ações de EA desenvolvidas em sociedade, principalmente nas escolas sobre o processo de reciclagem dos resíduos gerados, sua influência no meio em que vivemos e sobre como cada 
cidadão contribui para uma boa segregação e aproveitamento dos materiais (Correa et al., 2015).

Seguindo o mesmo pensamento, Ozorio et al. (2015) afirmam que o aluno atua como multiplicador de informações, isso significa dizer que leva para casa e para a sociedade tudo o que aprende e vive no ambiente escolar. Ainda, Reichert e Mendes (2014) descrevem que o correto gerenciamento dos RS é um dos principais desafios dos gestores públicos no início deste novo milênio, visto que o problema da disposição inadequada ainda permanece, principalmente nos pequenos municípios.

Quando questionados sobre a importância da separação dos resíduos, se observou que $93 \%$ dos alunos consideram esse ato extremamente importante, pois já haviam trabalho sobre esse tema. Os alunos mencionaram que a coloração específica das lixeiras (verde, amarelo, vermelho, azul e marrom) facilita o processo de separação adequada. O restante dos alunos, 7\%, responderam não ser importante a separação dos resíduos, com o pensamento de que tudo é enviado para o mesmo local. Para pensamentos como esse, Santos e Silva (2017) salientam que a falta de conhecimento sobre os impactos do lixo no meio ambiente ajuda nessa passividade. Os autores descrevem que para muitas pessoas, uma vez que o lixo sai dos domicílios, alguém está cuidando dele, e logo pensam que o problema está sendo resolvido, sem conhecer e dar importância como seus resíduos estão sendo tratados.

Devido à grande quantidade de resíduos produzidos diariamente, Monteiro et al. (2001), destacam que é enorme a preocupação com o destino dado a esses, pois quando incorretamente gerenciados tornam-se uma grave ameaça ao meio ambiente. Nesta percepção, Trindade (2011) descreve que trabalhar esse assunto nas escolas possibilita que o conhecimento agregado pelo aluno seja passado para o seu lar e para o convívio em sociedade, aumentando seu comprometimento e colaboração para a redução da geração dos resíduos sólidos e sua correta disposição final.

$\mathrm{Na}$ Figura 2 são apresentados os resultados obtidos sobre a porcentagem de resíduos que são produzidos nas residências dos alunos participantes do estudo. 


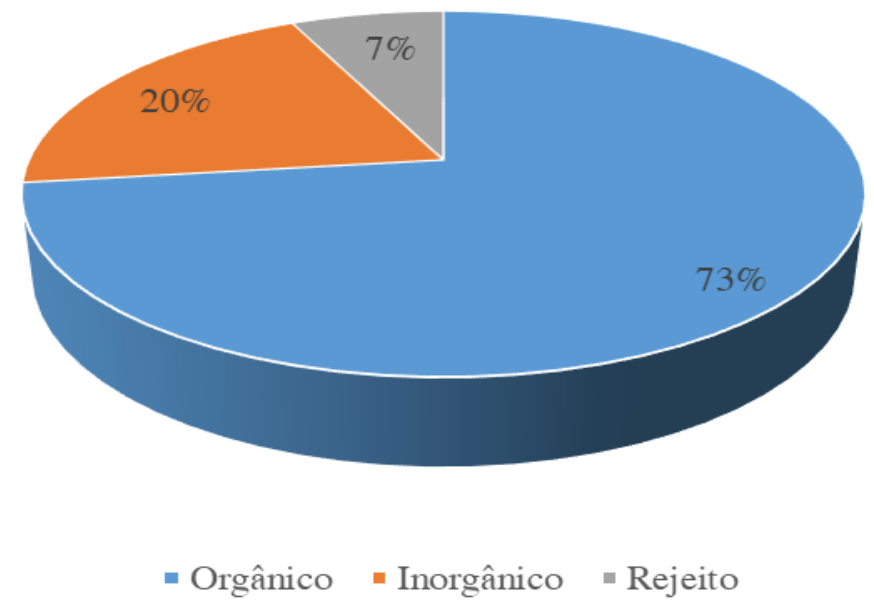

Figura 2. Porcentagem de resíduos produzidos nas residências dos alunos participantes do estudo.

Segundo informações de Casarin (2013), no Brasil, os componentes orgânicos somam cerca de $60 \%$ do peso total do resíduo coletado, ou seja, no presente estudo os alunos indicaram um percentual ainda superior à média nacional. Apesar do grande volume, estes podem ter outro fim, que não os aterros sanitários. Conforme Corrêa et al. (2015), é possível reciclar o lixo orgânico em quintais, escolas, empresas e até em apartamentos. Por meio da compostagem, os resíduos orgânicos podem ser transformados em adubo com grande capacidade de reposição de sais minerais e vitaminas, podendo ser utilizado, por exemplo, em plantas de jardins e hortas.

Os resíduos inorgânicos (secos), contemplando os materiais passíveis de reciclagem, corresponderam a 20\% (Figura 2). Infelizmente, este percentual de resíduos não é completamente reciclado, muitas vezes pela falta de pessoal ou estrutura deficitária nas usinas de triagem para separação de todo o material (COELHO, 2000). Contudo, a reciclagem pode amenizar os problemas relacionados à disposição final dos resíduos e ainda possibilita economizar energia, poupar recursos naturais e trazer de volta ao ciclo produtivo o que é jogado fora (Brasil e Santos, 2004)

Os rejeitos corresponderam a 7\% dos resíduos (Figura 2). Segundo Obladen et al. (2009), são assim classificados os resíduos que não podem ser reaproveitados ou valorizados em virtude de suas características ou devido à inexistência de tecnologias apropriadas. Resíduos provenientes de banheiros e embalagens cuja composição não permite reciclagem são exemplos e correspondem cerca de 20 a $25 \%$ dos resíduos destinados ao Consórcio Intermunicipal de Gestão Multifuncional, para o qual 
município de Três Passos envia seus resíduos para triagem e destinação final (Calderan, 2018).

Na Figura 3, os alunos foram questionados sobre a destinação dos resíduos orgânicos.

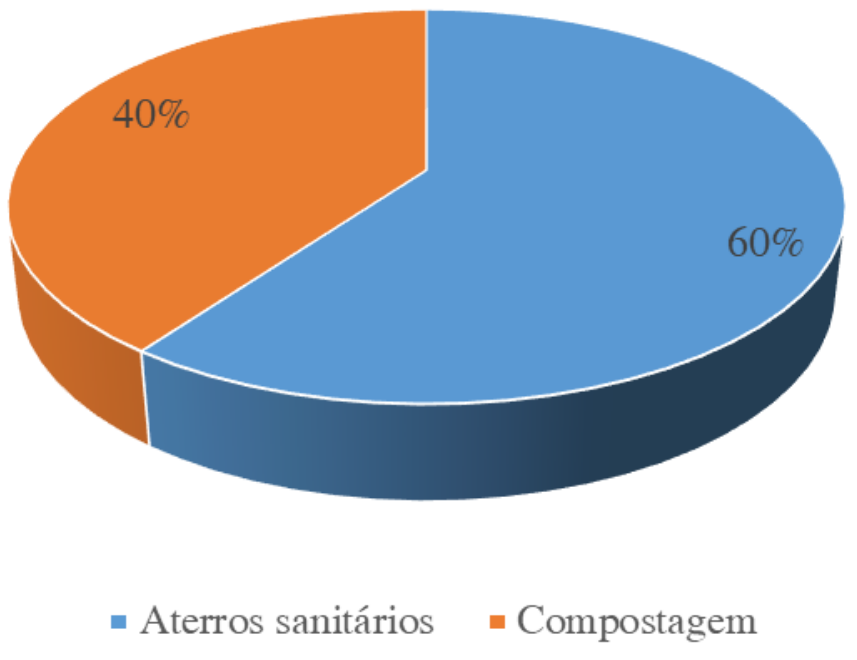

Figura 3. Destinação dos resíduos orgânicos gerados nas casas dos alunos participantes deste estudo.

Menos da metade das famílias dos alunos realizam a compostagem de seus resíduos orgânicos em casa. Se mais famílias adotassem práticas como está, reduziríamos a quantidade de resíduos orgânicos destinados a aterros sanitários, assim como gastos públicos com a coleta e disposição desses resíduos e potencializaríamos a geração de adubo orgânico para utilização em residências. Ao complementar estas informações, Frota et al. (2015) salientam que a reutilização dos resíduos é muito importante, pois além de evitarem sobrecargas nos aterros sanitários, possibilitam a segregação dos resíduos na fonte, diminuindo, assim, os riscos de contaminação dos materiais orgânicos a serem compostados.

Na Figura 4, os alunos foram questionados sobre a destinação dos inorgânicos. 


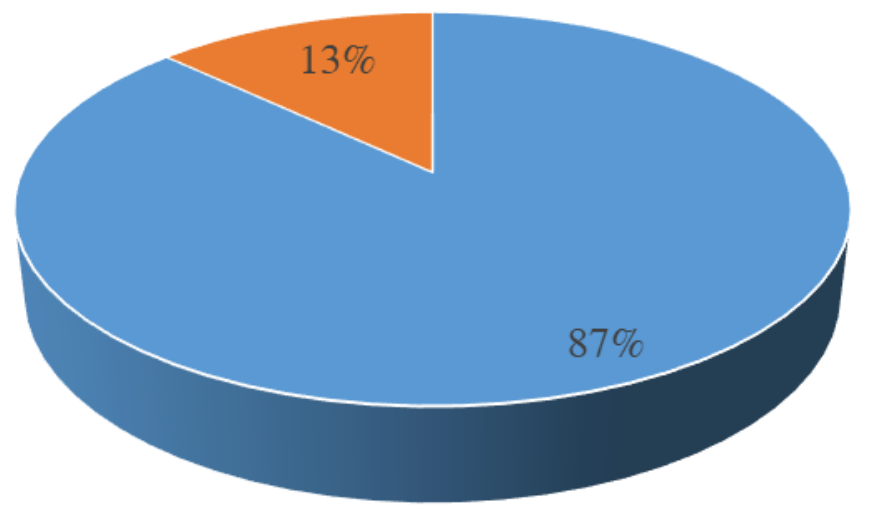

- Descarte em coletores - Reutilização doméstica

Figura 4. Destinação dos resíduos inorgânicos.

Observou-se que $87 \%$ descartam em coletores, o que posteriormente levar a segregação da composição do material inorgânico em plástico, papel, metal e vidro para posterior reciclagem. O que de acordo com Menezes e Resio (2011), evitam a sobrecarga nos aterros, devido a comercialização destes materiais. Já 13\% salientaram que reutilizam na forma de confecção de brinquedos, como: carrinhos, jogos e alguns utensílios. Diante dos impactos causados ao meio ambiente pela ação do ser humano, e da noção da finitude dos recursos naturais, a reciclagem é uma das alternativas encontradas na busca por um equilíbrio entre captação, produção e consumo (Menezes e Resio, 2011).

Durante a realização das oficinas sobre resíduos sólidos, os alunos se mostraram interessados e participativos nas atividades, que visavam apresentar o lixo como agente potencial de poluição, bem como os possíveis riscos à saúde pública.

Durante a realização de uma das palestras, as perguntas mais frequentes foram: o que é resíduo sólido? como é o processo de separação no centro de triagem da Região Celeiro? que tipo de resíduos produzimos? por que nossa cidade não tem oficina de reciclagem para os alunos desenvolverem atividades com esses materiais? dentre outras. As perguntas foram respondidas através de fotos, vídeos, folheto informativo e conversas, bem como, dando-se ênfase aos problemas causados no ambiente e na saúde coletiva pelo descarte incorreto dos resíduos.

Neste trabalho, o desenvolvimento de oficinas pedagógicas foi muito produtivo, pois favoreceu a dinâmica das atividades e permitiu maior motivação e participação dos 
alunos. Nestas oficinas foram desenvolvidos cartazes sobre os tipos de resíduos sólidos, bem como a produção de objetos/brinquedos/jogos por meio da reutilização desses materiais. Para consolidar o conhecimento, outras atividades lúdicas foram desenvolvidas, como a elaboração de poemas e um folder, os quais abordaram temas como a preservação do meio ambiente.

Os alunos também foram divididos em grupos e confeccionaram lixeiras coloridas para serem usadas na sala de aula. Ainda foi mostrado para os alunos vários artesãos brasileiros que utilizam materiais recicláveis para a produção de arte, como, Maria do Socorro Simões, Vik Muniz e Debora Muskratz. Esta informação permitiu a motivação dos alunos, os quais demonstraram interesse em construir suas próprias obras de arte. Os cartazes (Figura 5) e as lixeiras (Figura 6) confeccionadas pelos alunos podem ser observados abaixo.

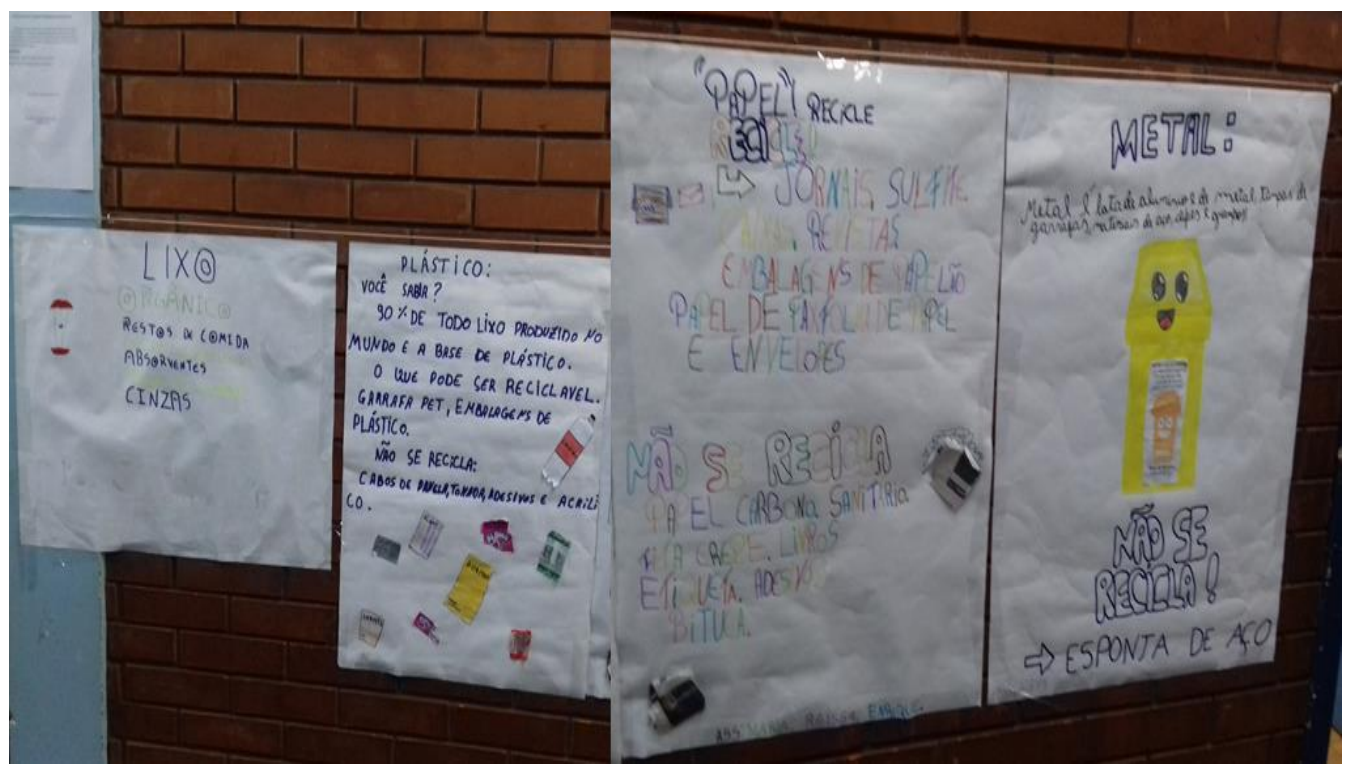

Figura 5. Cartazes confeccionados pelos alunos sobre os resíduos sólidos.

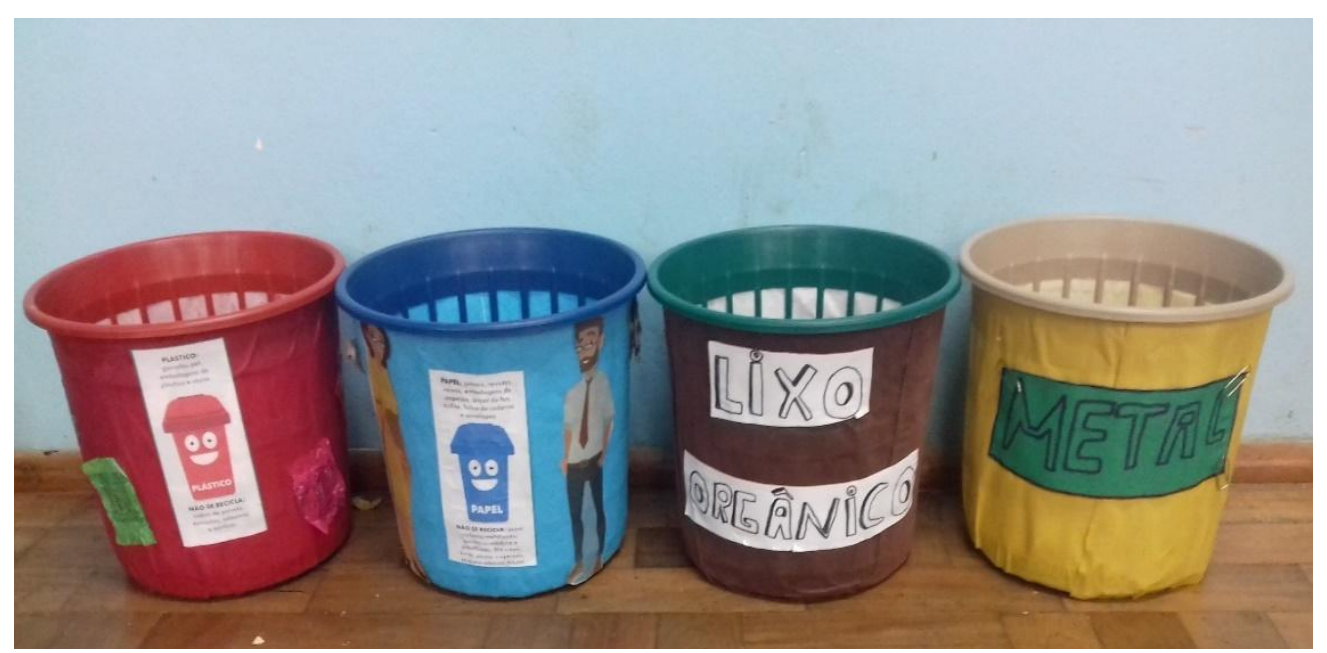

Figura 6. Lixeiras coloridas confeccionadas pelos alunos. 
Após o processo de sensibilização o questionário foi reaplicado para avaliar se as ações foram efetivas na melhoria do conhecimento e sensibilização dos alunos. Como resultados foi possível observar algumas mudanças nas respostas, como segue.

Quando indagados se era importante separar os resíduos, 100\% dos alunos disseram que sim, em detrimento a reposta anterior a sensibilização que foi de $93 \%$. Portanto, podendo se inferir que as atividades de sensibilização foram efetivas.

Diante disso, evidencia-se a importância do trabalho desenvolvido, o que é corroborado por Petry et al. (2015), os quais relatam que a gestão dos resíduos sólidos é um tema que vem sendo bastante discutido na atualidade, em razão das consequências do descaso em sua correta destinação. Nesse sentido é importante destacar que, de acordo com Santos e Silva (2017), os problemas relacionados aos RS estão concentrados nas atitudes da própria sociedade, ou seja, há a necessidade permanente de conscientizar a população, quanto à importância de colaborar com a coleta seletiva e destinar corretamente esses materiais, sempre procurando o melhor aproveitamento possível.

Na questão sobre a destinação dos resíduos orgânicos (Figura 7), houve uma mudança significativa quando comparada aos resultados anteriores a sensibilização (Figura 3).

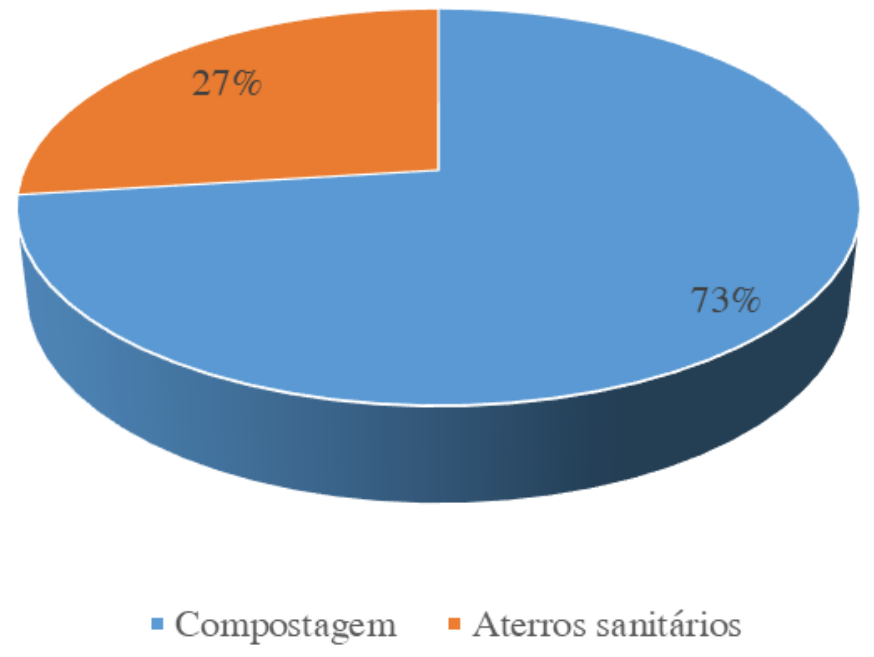

Figura 7. Destinação dos resíduos orgânicos nas residências dos alunos após as ações de sensibilização ambiental. 
Após a atividade de sensibilização, 73\% dos entrevistados declararam destinar os resíduos para o processo de compostagem e $27 \%$ aos aterros sanitários, enquanto antes da sensibilização $60 \%$ encaminhavam para o aterro e apenas $40 \%$ utilizavam os resíduos no processo de compostagem. Portanto, os resultados observados na Figura 7 demonstram a importância da sensibilização e do processo de compostagem pelos alunos. Estes resultados estão de acordo com os de Sá e Griggio (2016), que afirmaram que por meio da compostagem de resíduos orgânicos pretende-se que os estudantes percebam a conexão da química com as demais disciplinas, pertencentes às diferentes áreas do conhecimento. Ainda, que compreendam a importância das ações locais, individuais e coletivas, na preservação do meio ambiente e que os trabalhos realizados despertem sua consciência crítica, estimulando atitudes de menor impacto ambiental e social, dentro de suas possibilidades. Espera-se por fim, possibilitar aos alunos repensarem suas práticas diárias, construindo conceitos para aplicá-los na vida, ou, conforme Guimarães (2007), sensibilizar o educando de acordo com a sua realidade local, ou seja, trabalhar a vivência imediata para chegar a uma vivência plena.

Na questão sobre a destinação dos resíduos inorgânicos (Figura 8), houve uma mudança significativa quando comparada aos resultados anteriores a sensibilização (Figura 4).

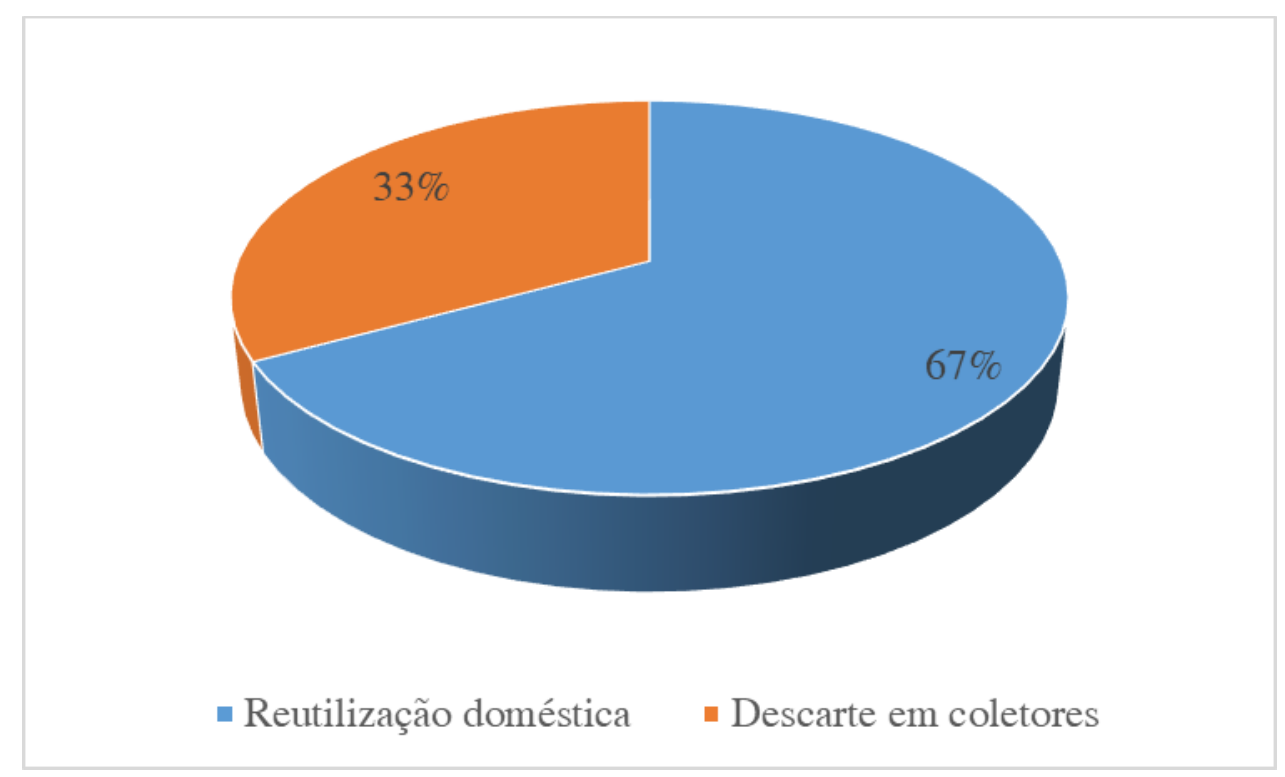

Figura 8. Destinação dos resíduos inorgânicos.

Após a atividade de sensibilização, 67\% dos entrevistados declararam reutilizar o material inorgânico e 33\% descartam em coletores, enquanto antes da sensibilização 
$13 \%$ reutilizavam e $87 \%$ descartavam os resíduos sem a preocupação de reutilizar o que fosse possível. Portanto, os mesmos destacaram que após a palestra e a oficina de materiais recicláveis, passaram a reutilizar os materiais em suas casas para a confecção de jogos e brinquedos.

O reaproveitamento dos RS observado neste trabalho é similar ao descrito por Santos e Silva (2017), assim como a interpretação de que as aulas de reciclagem fazem a diferença, pois permitem que às crianças aprendam todas as etapas da reciclagem, bem como a cuidar e preservar. Para Klein e Fiurini (2016), no dia a dia de uma sala de aula, podem ser mantidas as ações clássicas para trabalhar Educação Ambiental, como a separação de resíduos sólidos nas residências, a coleta seletiva para a reciclagem, por exemplo, entre outras. No entanto, essas ações devem ser o ponto de partida para uma reflexão mais profunda para concretizar uma educação ambiental mais crítica, tornando esses alunos agentes multiplicadores em suas casas. No mesmo sentido, as atividades de reciclagem e gestão de resíduos também visam preservar as matérias-primas e economizar energia no processo produtivo, pois quase todas as formas de produção de energia geram impactos ambientais significativos, além de evitar potenciais riscos de toxidade que possa afetar a saúde humana (Hatami-Marbini et al., 2013).

Por fim, após o processo de sensibilização, procedeu-se novamente a coleta e avaliação dos resíduos de forma individual nas lixeiras. Pode-se observar uma melhora significativa na separação dos RS da sala de aula, pois os resíduos antes eram armazenados todos misturados em um único coletor. Com a confecção dos coletores, conforme o tipo de resíduo, foi observado que esses passaram a ser descartados em local apropriado.

Após as ações de sensibilização, quando se repetiu a análise da composição gravimétrica dos resíduos gerados na sala de aula dos alunos, obteve-se 186 g. Apesar da baixa quantidade gerada, assim como da primeira vez (210 g), agora foi possível quantificar os resíduos de acordo com sua tipologia, devido à correta segregação, tendo sido verificado $110 \mathrm{~g}$ de papel, $62 \mathrm{~g}$ de plástico e $14 \mathrm{~g}$ de resíduos orgânicos, todos depositados de forma correta nos respectivos coletores. Estes resultados mostram que as crianças precisam ser incentivadas a fazer a separação dos resíduos de acordo com a coloração. Resultado este que corroboram ao exposto por Silva (2013) que destaca a importância de trabalhar em escolas a separação dos resíduos por diferentes cestos, representados por cor, onde cada material tem a sua própria cor. 
Portanto, diante dos resultados obtidos, pode-se inferir que os alunos do $5^{\circ}$ ano entenderam o quanto o processo de separação e de reciclagem dos RS é importante, pois o descarte incorreto dos resíduos pode degradar o meio ambiente.

\section{CONSIDERAÇÕES FINAIS}

Atividades de Educação Ambiental contribuem para a sensibilização dos alunos participantes dos projetos.

Atividades de Educação Ambiental nas escolas ampliam o conhecimento dos alunos e permitem melhorar a separação dos resíduos.

\section{REFERÊNCIAS}

BALDIN, A.C. Educação Ambiental: Desafios e Sucessos no Brasil e no Mundo. Limeira. 2015. 62 f. (Trabalho de Conclusão de Curso). Campinas/SP, Universidade Estadual de Campinas, Faculdade de Ciências Aplicadas, 2015.

BRASIL, A.M.; SANTOS, F. Equilíbrio ambiental e resíduos na sociedade moderna. São Paulo: Faarte Editora Ambiental, 2004, 223p.

BRASIL. Lei $\mathbf{n}^{0} 9.795$ de 27 de abril 1999. Dispõe sobre a educação ambiental, institui a Política Nacional de Educação Ambiental e dá outras providências. Brasília, 1999. Disponível em:www:https://www.camara.leg.br/proposicoesWeb/prop_mostrarintegra;jsessionid=5 0EE32BD99AF52EB7D5DB8E7E03AE765.node1 ?codteor=634068\&filename=Legisla caoCitada+-PL+4692/2009. Acesso em 26/março/2020.

CALDERAN, T.B. Consórcios intermunicipais: condições e possibilidades de atendimento da política nacional de resíduos sólidos (PNRS) a partir do princípio da visão sistêmica. 2018, 322 f. (Tese de Doutorado). Lajeado/RS. Programa de PósGraduação em Ambiente e Desenvolvimento, da Universidade do Vale do Taquari Univates, 2018. 
CASARIN, D.S. Diagnóstico dos resíduos sólidos urbanos no município de Morro

Redondo/RS. 2013. 53 f. (Trabalho de Conclusão de Curso). Pelotas/RS. Universidade Federal de Pelotas, 2013.

COELHO, H. Manual de gerenciamento de resíduos de serviços de saúde. Rio de Janeiro: Fiocruz, 2000. 85p.

CORRÊA, L.B. et al. Análise social de um Programa de Coleta Seletiva de Resíduos Sólidos Domiciliares. Revista Monografias Ambientais, v.14, n.2, p.193-201, 2015.

DIAS, S.M.F. Caracterização física dos resíduos sólidos urbanos: uma etapa preliminar no gerenciamento do lixo. In: XVIII Congresso Internacional de Inginiéria Sanitaria y ambiental. Cancún, México, 2002.

FELIX, R.A.Z. Coleta Seletiva em Ambiente Escolar. Revista Eletrônica do Mestrado em Educação Ambiental, v.18, n.1, p.56-71, 2007.

FIGUEIRÓ, P.S. Educação para a Sustentabilidade em cursos de graduação em Administração: proposta de uma estrutura analítica. 2015. 262 f. (Tese de Doutorado). Porto Alegre/RS, Curso de Pós-Graduação em Administração, Universidade Federal do Rio Grande do Sul, 2015.

FROTA, A.J.A. et al. Implantação de um sistema de coleta seletiva: aspectos legais e de sustentabilidade. Revista Gestão e Sustentabilidade Ambiental. v.4, n.1, p.129-155, 2015.

GUIMARÃES, M. A formação de educadores ambientais. Campinas: Editora Papirus, 2007.

HATAMI-MARBINI, A. et al. A fuzzy group Electre method for safety and health assessment in hazardous waste recycling facilities. Safety Science, v.51, n.1, p. 414426, 2013. 


\section{REALIZZAÇ,ÂO}

KGATHI, D.L.; BOLAANE, B. Instruments for sustainable solid waste management in

Botswana. Wate management \& research: journal of the International Solid Wastes Association, v.19, n.4, p.342-53, 2001.

MEDEIROS, A. B.et al. A Importância da educação ambiental na escola nas séries iniciais. Revista Faculdade Montes Belos, v.4, n.1, p.1-17, 2011.

MONTEIRO, J. H. P. et al. Manual Integrado de Gerenciamento de Resíduos Sólidos. Rio de Janeiro: Editora IBAM, 2001.

NARCIZO, K.R.S. Uma análise sobre a importância de trabalhar educação ambiental nas escolas. Revista Eletrônica de Mestrado em Educação Ambiental. v. 22, p.86-94, 2009.

OBLADEN, N. L. et al.; Guia para Elaboração de Projetos de Aterros Sanitários para Resíduos Sólidos Urbanos. Paraná: Editora CREA, 2009.

OZÓRIO, M. S. et al. Promovendo a conscientização ambiental: Resultados de uma pesquisa realizada com alunos do ensino médio sobre polímeros, plásticos e processos de reciclagem. Revista Brasileira de Educação Ambiental, v.10, n.2, p.11-24, 2015.

PETRY, D. R. et al. Gestão de Resíduos Sólidos: um estudo em uma empresa que atua na cidade de Xanxerê e região. Revista Eletrônica em Gestão, Educação e Tecnologia Ambiental, v.19, n.2, p. 682-702, 2015.

PONTALTI, E. S. Projeto de Educação Ambiental: Parque Cinturão Verde de Cianorte. Disponível me: http://www.apromac.org.br. Acesso em: 05/08/2020.

REICHERT, G.A.; MENDES, C.A.B. Avaliação do ciclo de vida e apoio a decisão em gerenciamento integrado e sustentável de resíduos sólidos urbanos. Revista de Engenharia Sanitária e Ambiental, v.19, n.3, p.301-313, 2014.

SÁ, M.B.Z.; GRIGGIO, M.S. Transformando lixo orgânico em adubo, preservando o meio ambiente e abordando conceitos químicos. Secretaria da Educação do Estado do Paraná, v.1, p.1-20, 2016. 
SANTOS, C.F; SILVA, A.J.A importância da educação ambiental no ensino infantil com a utilização de recursos tecnológicos. Revista Gestão e Sustentabilidade Ambiental. v.5, n.2, p.4-19, 2017.

SARAIVA, V.M. et al. A prática pedagógica do ensino de educação ambiental nas escolas públicas de João Câmera-RN. Revista Holos, v.2, n.24, p.81-93, 2008.

SATO, M. Educação Ambiental. São Carlos: Rima, 2002.

SILVA, M.M.P.; LEITE, V.D. Estratégias para realização de educação ambiental em escolas do ensino fundamental. Revista Eletrônica de Mestrado em Educação Ambiental. v. 20, p.371-392, 2008.

SILVA, N.F. Reciclagem: a sensibilização na escola. 2013, 31 f. (Monografia de graduação). Medianeira/PR, Universidade Tecnológica Federal do Paraná, 2013.

SILVEIRA, D.M. Educação infantil e meio ambiente: diálogo que gera conscientização. Revista Bem Legal, v.3, n.1, p. 49-56, 2013.

TRINDADE, N.A.D. Consciência Ambiental: coleta seletiva e reciclagem no meio ambiente escolar. Enciclopédia Biosfera. v.7, n.12, p.15, 2011.

UNESCO. Década das Nações Unidas da Educação para um Desenvolvimento Sustentável, 2005-2014: documento final do esquema internacional de implementação. Brasília: UNESCO, 2005. 120p.

ZAMORA, G.F. Análise do processo de reciclagem dos resíduos sólidos na cidade de Porto Alegre: Unidades de Triagem e os catadores.2013. 50 f. (Monografia de graduação). Porto Alegre/RS, Instituto de Geociências Departamento de Geografia, Universidade Federal do Rio Grande do Sul, 2013. 